\title{
QUANTIFICATION OF FUGITIVE REACTIVE ALKENE EMISSIONS FROM PETROCHEMICAL PLANTS WITH PERFLUOROCARBON TRACERS
}

\author{
Gunnar I. Senum and Russell N. Dietz \\ Environmental Science Department \\ Atmospheric Science Division \\ Brookhaven National Laboratory \\ Upton NY 11973-5000
}

Final Report to

Houston Advanced Research Center (HARC)

June 2004

Research by BNL investigators was performed under the auspices of the U.S. Department of Energy under Contract No. DE-AC02-98CH10886. 


\section{DISCLAIMER}

This report was prepared as an account of work sponsored by the United States Government. Neither the United States Government nor any agency thereof, nor any of their employees, nor any of their contractors, subcontractors or their employees, makes any warranty, express or implied, or assumes any legal liability or responsibility for the accuracy, completeness, or any third party's use or the results of such use of any information, apparatus, product, or process disclosed, or represents that its use would not infringe privately owned rights. Reference herein to any specific commercial product, process, or service by trade name, trademark, manufacturer, or otherwise, does not necessarily constitute or imply its endorsement, recommendation, or favoring by the United States Government or any agency thereof or its contractors or subcontractors. The views and opinions of authors expressed herein do not necessarily state or reflect those of the United States Government or any agency thereof. 


\section{Introduction}

Recent studies demonstrate the impact of fugitive emissions of reactive alkenes on the atmospheric chemistry of the Houston Texas metropolitan area (1). Petrochemical plants located in and around the Houston area emit atmospheric alkenes, such as ethene, propene and 1,3butadiene. The magnitude of emissions is a major uncertainty in assessing their effects. Even though the petrochemical industry reports that fugitive emissions of alkenes have been reduced to less than $0.1 \%$ of daily production, recent measurement data, obtained during the TexAQS 2000 experiment indicates that emissions are perhaps a factor of ten larger than estimated values. Industry figures for fugitive emissions are based on adding up estimated emission factors for every component in the plant to give a total estimated emission from the entire facility. The dramatic difference between estimated and measured rates indicates either that calculating emission fluxes by summing estimates for individual components is seriously flawed, possibly due to individual components leaking well beyond their estimated tolerances, that not all sources of emissions for a facility are being considered in emissions estimates, or that there are known sources of emissions that are not being reported. This experiment was designed to confirm estimates of reactive alkene emissions derived from analysis of the TexAQS 2000 data by releasing perfluorocarbon tracers (PFTs) at a known flux from a petrochemical plant and sampling both the perfluorocarbon tracer and reactive alkenes downwind using the Piper-Aztec research aircraft operated by Baylor University.

PFTs have been extensively used to determine leaks in piplines, air infiltration in buildings, and to characterize the transport and dispersion of air parcels in the atmosphere. Over 20 years of development by the Tracer Technology Center (TTC) has produced a range of analysis instruments, field samplers and PFT release equipment that have been successfully deployed in a large variety of experiments. PFTs are inert, nontoxic, noncombustible and nonreactive. Up to seven unique PFTs can be simultaneously released, sampled and analyzed and the technology is well suited for determining emission fluxes from large petrochemical facilities.

The PFT experiment described here was designed to quantitate alkene emissions from a single petrochemical facility, but such experiments could be applied to other industrial sources or groups of sources in the Houston area. 


\section{Experimental Procedure}

\section{Measurement of the reactive alkene fugitive emission factor of an individual plant}

The analysis of the TexAQS 2000 data provided a preliminary alkene (propene and ethene) emission flux from the Conoco/Phillips Sweeny petrochemical plant in Old Ocean, Texas. This flux was calculated from measurements of the concentrations of ethene, propene and $\mathrm{NO}_{\mathrm{x}}$ in the plume downwind from the plant. An alkene emission flux of about ten times larger than estimated was found (1).

In this project, the reactive alkene flux from the Sweeny facility is estimated by releasing PFTs at known rate from the plant. The reactive alkenes and the PFT concentrations were estimated from canister samples collected by aircraft flying in the plume downwind of the plant. Alkene emission fluxes, [alkene]flux, were calculated from

$$
[\text { alkene }]_{\mathrm{flux}}=\left([\text { alkene }]_{\mathrm{conc}} /[\mathrm{PFT}]_{\mathrm{conc}}\right)[\mathrm{PFT}]_{\mathrm{flux}}
$$

where ( [alkene $]_{\text {cond }} /[\mathrm{PFT}]_{\text {conc }}$ ) is the concentration ratio measured in downwind samples and [PFT] flux is the known PFT emission flux at the plant. This assumes that the emission sources of the reactive alkenes and PFTs are collocated. Concentrations of PFTs and reactive alkenes measured downwind were corrected for background concentrations measured upwind. Measurements were made in the fall of 2003. The experimental approach is detailed in the following sections.

\section{$\underline{\text { PFT Emission Flux }}$}

The PFT emission flux from the plant must be sufficient so that PFT concentrations are quantifiable in 6-L canister samples collected in downwind plume. The dilution factor was estimated from measurements downwind of the Sweeny plant made during the TexAQS 2000 experiment. Typical $\mathrm{NO}_{2}$ concentrations were $3 \mathrm{ppb}(\mathrm{v})$. From an $\mathrm{NO}_{2}$ emission of 5108 tons/y as given in an 1999 EPA AIRS inventory, the $\mathrm{NO}_{2}$ emission rate is equivalent to $4700 \mathrm{~L}$ (gas phase)/min. Thus, an emission of $4700 \mathrm{~L} / \mathrm{min}$ yielded $3 \mathrm{ppb}(\mathrm{v})$ in aircraft sampling. We chose a PFT emission rate to yield a concentration well above the background. PFTs chosen for this experiment were perfluorodimethylcyclobutane, commonly called PDCB and perfluoromethylcyclopentane, commonly called PMCP. The PDCB is composed of two isomers and the gas chromatographic (GC) system used to analyze PFTs can be set to separate these isomers. PDCB has a background of $2.0 \mathrm{ppq}$ (parts per quadrillion or parts per $10^{15}$ ), composed of about $72.5 \%$ 1,2 PDCB and 27.5\% 1,3 PDCB. PMCP has an ambient background of 9.5 ppq. A possible advantage of using PDCB is that it is composed of two resolvable PFTs (equivalent to two tracers) whereas PMCP is a single component PFT. 


\section{$\underline{\text { PFT Release Cylinder Preparation }}$}

Based on the above preliminary transport and dilution calculation two cylinders of PFT release gases were prepared, one with PDCB and one with PMCP. The aluminum cylinders have a capacity of $137 \mathrm{cu}$ feet at $1800 \mathrm{psi}$. Based on dew point considerations it was decided to prepare the cylinders with a total pressure of 200 psi, in order to avoid condensing liquid PFT as the cylinder pressure dropped. Consequently, only $15.2 \mathrm{cu} \mathrm{ft}$ or 430 liters of release gas were prepared for each tracer.

The PFT release gases were prepared by first by removing dissolved gases from the liquid PFTs. The PFT can dissolve about an equal volume (STP) of air per volume of liquid PFT. The dissolved air was removed by repeated freeze-thaw cycles until the vapor pressure of the PFT was reached. For PDCB, 126.6 grams (PCR lot 5479) were volatilized into a pre-evacuated (less than 0.2 torr) cylinder (Cylinder ID CC15276) and pressured with $99.9 \%$ nitrogen for a design concentration of 24,200 ppm. Likewise, 114 grams of PMCP ( 3 bottles of PCR >90\% PMCP, lot 12483-4, and remainder Flutec PP1/2, 2/23/88 PP1/2(B)) were volatized into cylinder CC4921 for a design concentration of $20,990 \mathrm{ppm}$.

The PFT release gases were analyzed on a HP 5890 gas chromatograph, with a Carbochrom capillary column with a thermal conductivity detector. Analysis of the prepared cylinders with both pure liquid PFTs and earlier analyzed standards indicated a measured concentration for PDCB of 22,212 ppm and 21,415 ppm for PMCP.

The PFT release cylinders contained $430 \mathrm{~L}$ (STP) of PFT tagged gas. The release at the Sweeny Plant was chosen to be $50 \mathrm{~mL} / \mathrm{min}$ which was sufficient to provide 18 eight-hour-days of release for both PFTs.

\section{PFT Release Deployment}

The PFT release cylinders were shipped to the Sweeny plant in Old Ocean, Texas with regulators and calibrated flow restrictors. The regulator output pressure was set to provide 50 $\mathrm{mL} / \mathrm{min}$ of flow through the flow restrictor. An electronic flowmeter was also sent to Sweeny for measurement of the PFT release rate on flight days.

During a July 2003 visit to Sweeny plant, two release sites were selected. The first site was near the compressors, the GPS coordinates were $29^{\circ} 04.640^{\prime} \mathrm{N}$ and $95^{\circ} 44.683^{\prime} \mathrm{W}$. This site was chosen since the compressors were identified as a possible source of leaking alkene. The PDCB source was placed at this site. The release cylinder was mounted at ground level and 10 foot section of 1/8 inch polyurethane tubing was used to raise the release height. The PFT release flow rate was checked at the flow restrictor and at the end of the 10 foot section and were found to be the same. The inlet of the water chiller was chosen as the release site for the PMCP tracer. The GPS coordinates were $29^{\circ} 04.686^{\prime} \mathrm{N}$ and $95^{\circ} 44.718^{\prime} \mathrm{W}$. Again, it was thought the water chiller was possibly a source of alkene. At this site the cylinder was placed at ground level and 
again about 20 foot of polyurethane tubing was used to position the release as close as possible to the water chiller inlet. During setup, the flow measured at the flow restrictor and the release point at the end of the 20 feet of tubing, were identical.

A secondary effort in this study was to estimate the $\mathrm{NO}_{\mathrm{y}}$ emission flux, the GPS coordinates of the power plant, emitting the majority of the $\mathrm{NO}_{\mathrm{y}}$ was $29^{\circ} 04.368^{\prime} \mathrm{N}$ and $95^{\circ}$ $44.732^{`} \mathrm{~W}$, about 1933 feet from the PDCB release site.

A release protocol was developed and implemented. The sampling aircraft flew on days with appropriate wind direction and speed. On favorable days a call was placed to Sweeny before 11 AM. The two PFT release cylinders were opened at the cylinder head at least two hours before the aircraft arrived to assure that the tracer was transported downwind to the sampling area. An electronic flowmeter was used to control the flowrate to $50 \pm 5 \mathrm{~mL} / \mathrm{min}$; it only had to be adjusted once during the study. At the end of the sampling day, the flow was again measured and both cylinders were turned off.

\section{Aircraft PFT Sampling Protocol}

Replicate 6-L samples were taken aboard the Piper-Aztec, one for PFT analyses and the other for alkene and other hydrocarbon analyses. The aircraft sampling was a Texas Commission on Environmental Quality (TCEQ)/Baylor Unitersity effort. The aircraft flew four sampling runs under favorable synoptic conditions. The wind had to be from the SE to $S$ to ensure that there was minimal background concentration of alkenes from upwind sources. Winds had to range from 5 to $10 \mathrm{mph}$ to produce a well-defined downwind plume. On these days, a call was made to Sweeny to turn on the release cylinders and the aircraft air sampling instruments were turned on and calibrated. The aircraft also measured $\mathrm{NO}, \mathrm{NO}_{2}, \mathrm{NO}_{\mathrm{y}}$, ozone, and the standard meteorological variables. A RAD monitor (Reactive Alkene Detector), provided a measure of the total alkene concentration and was used to locate the alkene plume and to determine when to open the sampling canisters(3).

Table 1 lists the dates of the four sampling flights. On each of these flights, samples were taken both upwind and downwind of the Sweeny plant. The upwind sample was used to measure the background PFT and alkene concentrations. The downwind plume samples were expected to contain both the emitted alkene and PFT. The sample time and aircraft event number is given for each sample. The GPS location of the aircraft at the start of sampling and the downwind distance from the PMCP tracer release site is also given. Note that there is only one downwind sample in the 11/20/2003 flight, because the plume could not be located according to the real time RAD monitor. After this flight, the flight plan was revised to increase the probability of locating the alkene plume. Generally the first downwind sample was about 1.5 miles downwind of Sweeny, and the second about 4 miles downwind. 
Table 1

\begin{tabular}{|c|c|c|c|c|c|c|c|c|}
\hline \multirow{3}{*}{$\begin{array}{l}\text { Date } \\
\text { Numbe }\end{array}$} & \multirow[t]{3}{*}{ Event } & \multirow{3}{*}{$\begin{array}{r}\text { Sample } \\
\text { Type } \\
\end{array}$} & \multicolumn{2}{|c|}{ Sampling } & \multicolumn{2}{|c|}{ Location } & \multirow{2}{*}{\multicolumn{2}{|c|}{$\begin{array}{c}\text { Distance to } \\
\text { PMCP } \\
\text { release }\end{array}$}} \\
\hline & & & \multirow[t]{2}{*}{ Start } & \multirow[t]{2}{*}{ End } & \multirow[t]{2}{*}{ Lat.(N) } & \multirow[t]{2}{*}{ Long.(W) } & & \\
\hline & & & & & & & km & miles \\
\hline \multirow[t]{2}{*}{$11 / 20 / 2003$} & 10 & Upwind & 14:49:08 & $14: 49: 29$ & 29.042212 & 95.75304413 & 4.06 & 2.52 \\
\hline & 15 & Downwind & $15: 14: 53$ & $15: 15: 14$ & 29.105884 & 95.75960159 & 3.38 & 2.10 \\
\hline \multirow[t]{3}{*}{$11 / 25 / 2003$} & 21 & Upwind & $14: 24: 03$ & $14: 24: 24$ & 29.039551 & 95.76618576 & 4.74 & 2.95 \\
\hline & 27 & Downwind & $14: 54: 50$ & $14: 55: 11$ & 29.098845 & 95.76366425 & 2.91 & 1.81 \\
\hline & 34 & Downwind & $15: 17: 30$ & $15: 17: 51$ & 29.105448 & 95.72710800 & 3.52 & 2.18 \\
\hline \multirow[t]{3}{*}{$12 / 07 / 2003$} & 6 & Upwind & 13:59:01 & 13:59:22 & 29.034008 & 95.72785568 & 5.19 & 3.22 \\
\hline & 25 & Downwind & $14: 54: 03$ & $14: 54: 24$ & 29.100316 & 95.74945323 & 2.50 & 1.55 \\
\hline & 30 & Downwind & $15: 09: 45$ & $15: 10: 06$ & 29.136886 & 95.74980164 & 6.55 & 4.07 \\
\hline \multirow[t]{5}{*}{$12 / 14 / 2003$} & 11 & Upwind & $14: 25: 50$ & $14: 26: 11$ & 29.035739 & 95.71270498 & 3.51 & 2.18 \\
\hline & 27 & Downwind & $15: 16: 24$ & $15: 16: 45$ & 29.100049 & 95.75495529 & 2.61 & 1.62 \\
\hline & 32 & Downwind & $15: 43: 16$ & $15: 43: 37$ & 29.132086 & 95.76791763 & 6.39 & 3.97 \\
\hline & & & \multicolumn{2}{|c|}{ PMCP Release Site } & 29.07810 & 95.745300 & & \\
\hline & & & \multicolumn{2}{|c|}{ PDCB Release Site } & 29.07733 & 95.744717 & & \\
\hline
\end{tabular}

\section{PFT Analysis}

PFT canister samples were returned to the TTC at BNL for analysis. Table 2 gives the sampling date, event number, canister ID, and the initial canister pressure. The canisters were at sub-ambient pressure. Samples were extracted from canisters by pressurizing to two atmospheres with nitrogen. The last column is the amount of added nitrogen. This nitrogen had been previously analyzed on the PFT analysis system and verified as being free of PFT.

Three samples from each PFT canister were trapped on a CATS (Capillary Adsorbent Tracer Sampler), which is a small tube containing Ambersorb, a carbonaceous adsorbent which quantitatively collects any PFT in an air sample that is passed through it. The sample was withdrawn from the canister into a clean 1 liter sampling bag; which was then pumped through a CATS. After each sample the bag was purged with clean nitrogen and evacuated with a pump. This procedure was first tested with a blank canister filled with ambient air. The PFTs on the CATS were then thermally desorbed, separated by high-resolution GC and quantified by an ECD (electron capture detector). An exact transfer volume in this procedure need not be measured since the ambient background concentration of PMCH (perfluoromethylcyclohexane) in samples serves as an internal standard as explained below. After each sample, the bag was purged with clean nitrogen and evacuated with a pump. Chromatographic conditions were set to analyze only $\mathrm{PDCB}, \mathrm{PMCP}$ and PMCH (perfluoromethylcyclohexane), the first two were released from the 
Table 2

\begin{tabular}{cccccc}
\hline Date & $\begin{array}{c}\text { Event } \\
\text { Number }\end{array}$ & $\begin{array}{c}\text { Sample } \\
\text { Type }\end{array}$ & $\begin{array}{c}\text { Canister } \\
\text { ID }\end{array}$ & $\begin{array}{c}\text { Sample } \\
\text { Pressure } \\
\text { Torr }\end{array}$ & $\begin{array}{c}\text { Added } \\
\text { Nitrogen } \\
\text { psi }\end{array}$ \\
\hline $11 / 20 / 2003$ & 10 & Upwind & A-61 & 613 & 14.2 \\
& 15 & Downwind & N-79 & 611 & 14.1 \\
$11 / 25 / 2003$ & 21 & Upwind & SJV-120 & 607 & 14.1 \\
& 27 & Downwind & H-179 & 608 & 14.1 \\
& 34 & Downwind & 29 & 617 & 14.2 \\
$12 / 07 / 2003$ & 6 & Upwind & I-53 & 614 & 14.1 \\
& 25 & Downwind & K-151 & 602 & 14.1 \\
& 30 & Downwind & 102 & 583 & 14.4 \\
$12 / 14 / 2003$ & 11 & Upwind & H-102 & 622 & 14 \\
& 27 & Downwind & S-131 & 607 & 14.5 \\
& 32 & Downwind & DU98102 & 604 & 14.5 \\
\hline
\end{tabular}

plant; PMCH was not released but is has a constant, well measured ambient background concentration and is used here as an internal standard to account for dilution of the samples and enable the calculation of the actual PDCB and PMCP concentrations in the plume.

Figure 1 is a chromatogram of a nominal 100 femtoliter PFT standard which contains the first three PFTs. There are four peaks, the first two being the two isomers of PDCB, the third is $\mathrm{PMCP}$ and the last is $\mathrm{PMCH}$, the internal standard. The numbers in green at the top are the retention times and the red ticks on the baseline are integration events. The analysis is complete in about 14 minutes, and is automated in batches of 23 analyses. Typically, a few of these 23 are PFT standards (as in Figure 1) and others are of ambient air (a chromatogram of the PFTs at their ambient concentrations). Such samples provide the necessary checks on the analysis system.

The results of the PFT analysis are given in Table 3. The first column gives the sample name and event number (see Table 2). The second column is a CATS ID, a unique number to track the samples. The last 8 columns are the retention times and area counts for the four peaks as illustrated in Figure 2. Each canister has three rows in this table since each canister yielded three samples; the third sample was generally the largest in volume. This is because it was initially expected that the PFT concentrations would be higher for the first two samples, more or less one liter samples. After the first two analyses for each canister was completed it was decided, based on the results to analyze the remainder as one sample. Note that several PFT standards and ambient air standard are included in these tables, since they are associated with this grouping of samples. 


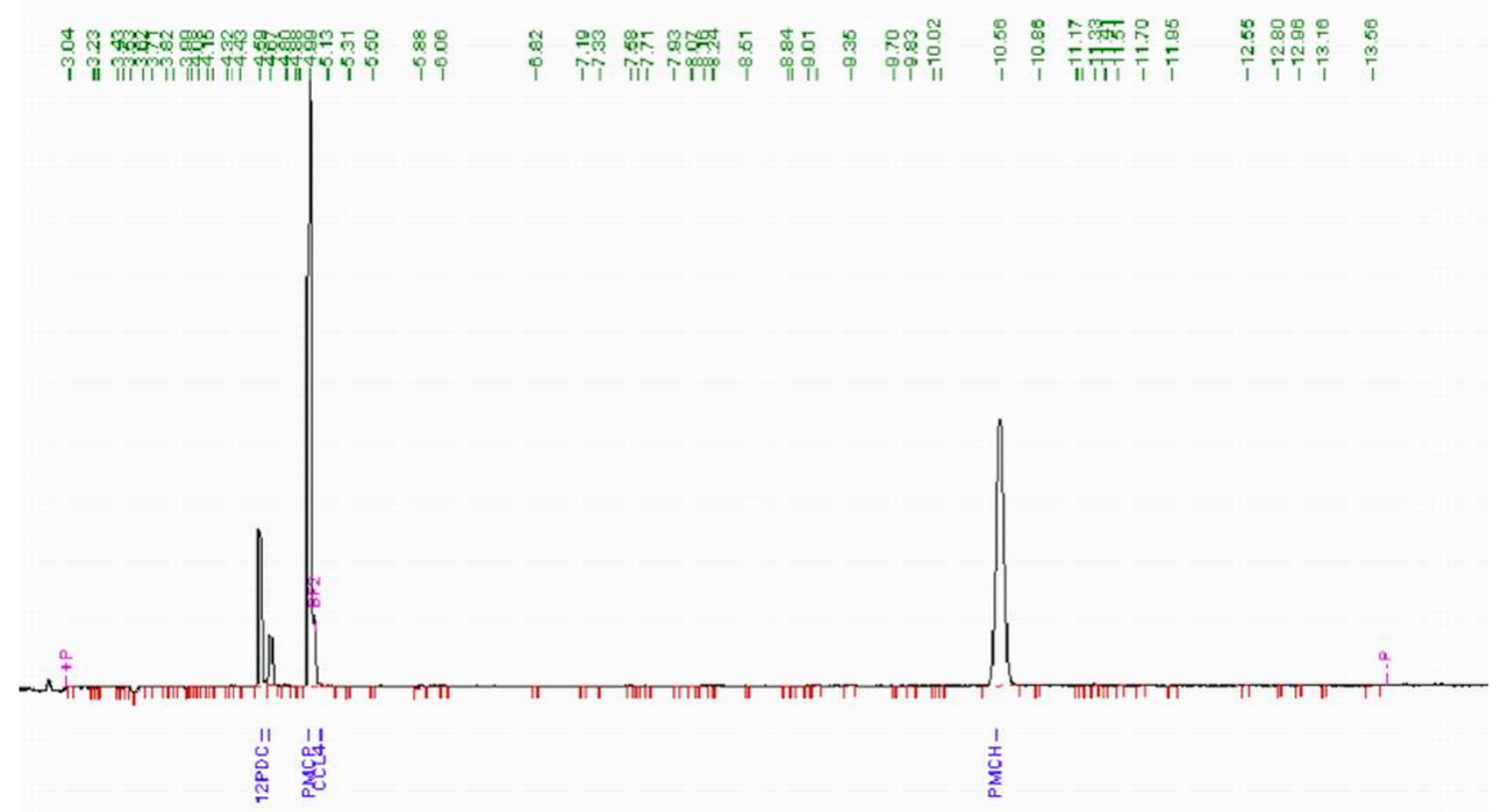

Figure 1

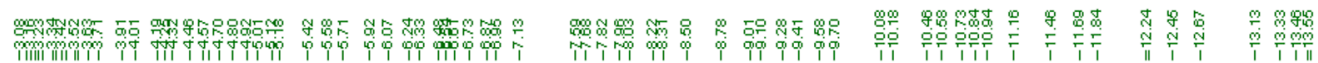

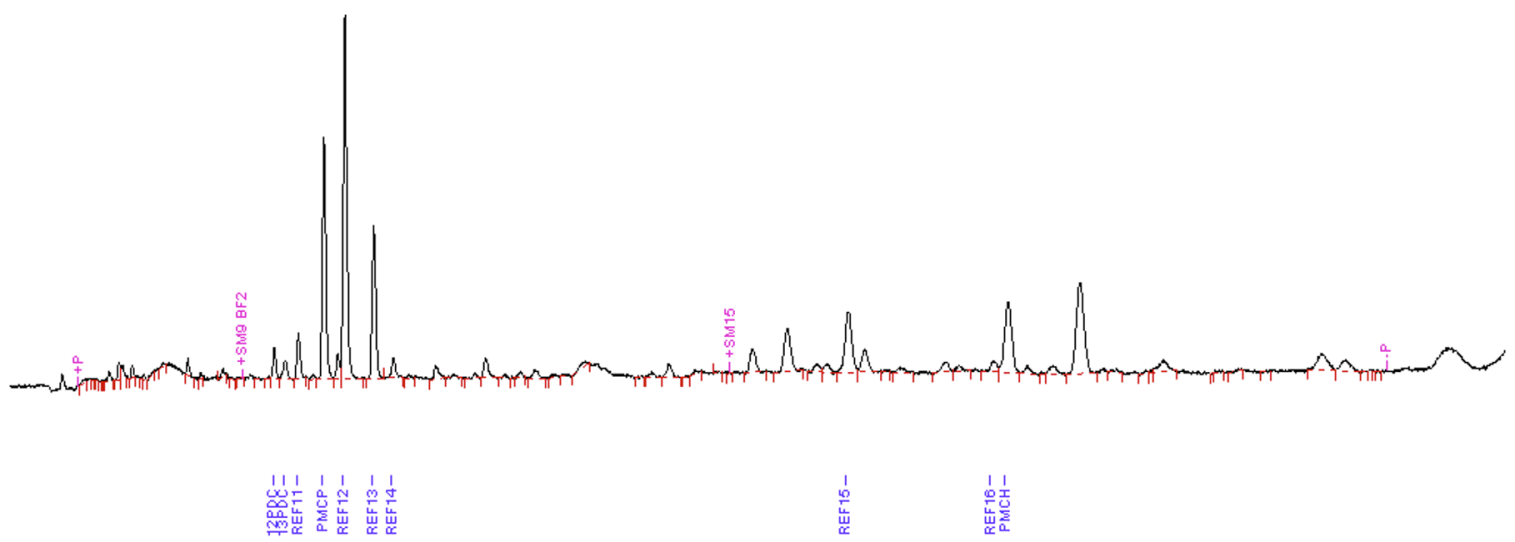

Figure 2 
Table 3

\begin{tabular}{|c|c|c|c|c|c|c|c|c|c|}
\hline \multirow[t]{3}{*}{ Sample Name } & \multirow[t]{3}{*}{ ID } & \multicolumn{3}{|c|}{ PDCB } & \multicolumn{3}{|c|}{ PMCP } & \multicolumn{2}{|c|}{ PMCH } \\
\hline & & \multicolumn{3}{|c|}{1,2} & \multicolumn{5}{|l|}{1,3} \\
\hline & & ret time & area & ret time & area & ret time & area & ret time & area \\
\hline A-61 & $\# 12610$ & 4.566 & 274.86 & 4.663 & 632.35 & 4.966 & 2022.66 & 10.476 & 934.82 \\
\hline A-61 & $\# 1014$ & 4.571 & 222.29 & 4.667 & 592.75 & 4.971 & 1864.75 & 10.486 & 863.17 \\
\hline A-61 & \#2129 & 4.609 & 1233.23 & 4.706 & 2687.02 & 5.012 & 7596.35 & 10.57 & 4283.07 \\
\hline $\mathrm{H}-102$ & \#1591 & 4.565 & 240.61 & 4.661 & 525.5 & 4.964 & 2221.37 & 10.477 & 1058.16 \\
\hline $\mathrm{H}-102$ & \#12851 & 4.604 & 1080.2 & 4.701 & 1970.75 & 5.007 & 7711.8 & 10.56 & 4370.77 \\
\hline $\mathrm{I}-53$ & $\# 4406$ & 4.570 & 235.89 & 4.666 & 620.94 & 4.970 & 2230.74 & 10.491 & 1004.74 \\
\hline $\mathrm{I}-53$ & \#2129 & 4.564 & 257.51 & 4.66 & 414.46 & 4.965 & 1769.44 & 10.49 & 875.27 \\
\hline $\mathrm{I}-53$ & \#1591 & 4.596 & 1035.08 & 4.692 & 1542.25 & 4.998 & 6751.37 & 10.548 & 3723.89 \\
\hline SJV-120 & \#8113 & 4.567 & 943.96 & 4.663 & 4430.5 & 4.966 & 3795.39 & 10.484 & 1158.21 \\
\hline SJV-120 & \#12851 & 4.577 & 1483.96 & 4.674 & 5861.5 & 4.977 & 4624.36 & 10.496 & 1598.76 \\
\hline SJV-120 & \#866 & 4.616 & 4368 & 4.715 & 16814.56 & 5.020 & 13331.84 & 10.59 & 5105.14 \\
\hline 25 uL El8 & $25 \mathrm{fL}$ & 4.595 & 24045 & 4.68 & 9256 & 4.997 & 102056 & 10.551 & 99305 \\
\hline N-79 & 2129 & 4.595 & 319.3 & 4.68 & 1008.9 & 4.993 & 2964.2 & 10.52 & 1388.8 \\
\hline $\mathrm{N}-79$ & & 4.587 & 466.6 & 4.683 & 1153.3 & 4.987 & 3247.5 & 10.526 & 1802.6 \\
\hline N-79 & 1607 & 4.595 & 883.5 & 4.691 & 2128.4 & 4.996 & 8695 & 10.54 & 2901.05 \\
\hline $\mathrm{H}-179$ & 12851 & 4.601 & 1832.2 & 4.698 & 6152.1 & 5.003 & 4699 & 10.527 & 1762.6 \\
\hline $\mathrm{H}-179$ & & 4.593 & 2219.4 & 4.69 & 7657.1 & 4.995 & 6484.2 & 10.549 & 1884.5 \\
\hline $\mathrm{H}-179$ & 4406 & 4.582 & 5145.8 & 4.679 & 15320.7 & 4.982 & 14044 & 10.501 & 3931.46 \\
\hline K-151 & 1591 & 4.608 & 508 & 4.705 & 1037 & 5.010 & 3472 & 10.561 & 1562.74 \\
\hline K-151 & & 4.599 & 417.4 & 4.695 & 1009.9 & 5.001 & 3320.5 & 10.537 & 1600.65 \\
\hline K-151 & 8113 & 4.605 & 734.22 & 4.7 & 1499.61 & 5.006 & 8563.87 & 10.557 & 2409.07 \\
\hline S-131 & 10325 & 4.605 & 478.4 & 4.702 & 992.2 & 5.007 & 3275 & 10.562 & 1729.6 \\
\hline S-131 & 907 & 4.592 & 539.2 & 4.688 & 1003.6 & 4.993 & 3394 & 10.54 & 1681.2 \\
\hline S-131 & 12610 & 4.608 & 1058.14 & 4.704 & 1749.72 & 5.011 & 9607 & 10.566 & 3206.1 \\
\hline 29 & 12610 & 4.562 & 2414 & 4.657 & 10391 & 4.959 & 5619 & 10.46 & 2386.7 \\
\hline 29 & 9928 & 4.594 & 2717.9 & 4.69 & 12523.5 & 4.994 & 6008.3 & 10.53 & 1972.06 \\
\hline 29 & 3516 & 4.570 & 1376.9 & 4.664 & 6160.9 & 4.957 & 4798.5 & 10.47 & 1011.44 \\
\hline DU98102 & 11406 & 4.564 & 598 & 4.659 & 1000.2 & 4.983 & 3514 & 10.47 & 1573.3 \\
\hline DU98102 & 11036 & 4.569 & 673.1 & 4.662 & 1196 & 4.968 & 4258.3 & 10.493 & 2154.4 \\
\hline DU98102 & 5337 & 4.608 & 1209.52 & 4.704 & 1772.22 & 5.011 & 10097.3 & 10.569 & 3402 \\
\hline 102 & 5337 & 4.570 & 470 & 4.665 & 1043 & 4.989 & 3272 & 10.48 & 1706.1 \\
\hline 102 & 12043 & 4.548 & 538.7 & 4.644 & 1028.7 & 4.947 & 3216.95 & 10.447 & 1497.22 \\
\hline 102 & 11406 & 4.601 & 620.66 & 4.696 & 1699.21 & 5.001 & 5208.47 & 10.545 & 2703.2 \\
\hline 1 Liter BNL air & & 4.570 & 477.6 & 4.652 & 158.99 & 4.969 & 2527.7 & 10.469 & 2444.7 \\
\hline 1 Liter BNL.air & & 4.573 & 472.78 & 4.656 & 331.5 & 4.973 & 4512.4 & 10.497 & 2275.4 \\
\hline 1 Liter BNL air & & 4.594 & 449.61 & 4.675 & 297.22 & 4.994 & 4730.85 & 10.535 & 2399.09 \\
\hline 1 Liter BNL air & & 4.567 & 482.2 & 4.651 & 488.1 & 4.968 & 4361.4 & 10.51 & 2470.63 \\
\hline 1 Liter BNL air & & 4.576 & 459.46 & 4.663 & 341.18 & 4.977 & 5474.91 & 10.495 & 2452.69 \\
\hline
\end{tabular}


The chromatogram in Figure 1 is from a PFT standard. Figure 2 shows the chromatogram of canister sample H-102. Note that there are more peaks in this chromatogram than can be attributed to the released PFTs, or the internal standard. The identification in blue, below the baseline, gives the location of the PFTs and of peaks that always appeared in the ambient air chromatograms, labeled with a reference number. There are some unexpected peaks, and these are most likely compounds unique to the sampling region as they were consistently found in all of the samples. These are most likely, higher than ambient concentrations of chlorofluorocarbons and elevated hydrocarbons. No attempt was made to identify these compounds. Unfortunately, one of these unexpected peaks was unresolvable from 1,3 PDCB, one of the two isomers of PDCB, consequently the 1,3 PDCB results cannot be used. But 1,2 PDCB, PMCP and PMCH are all fully resolved as verified by carefully measuring the widths of the peaks and comparing them with those in the PFT standard. Any increased in width is due to a coincidence with an unresolved compound. The chromatographic integration technique was refined with several iterations because of the increased in the number of "new" peaks in the samples. The chromatograms were inspected to verify correct integration of the peaks.

To factor out the sample dilution the area counts for PDCB and PMCP were divided by the PMCH area counts. The resulting values were then averaged for the triplicate PFT analysis for each canister, and the results are given in Table 4.

Table 4

\begin{tabular}{cccccc}
\hline Date & Event Number & $\begin{array}{c}\text { Sample } \\
\text { Type }\end{array}$ & $\begin{array}{c}\text { Canister } \\
\text { ID }\end{array}$ & $\begin{array}{c}\text { PDCB/PMCH } \\
\text { area ratio }\end{array}$ & $\begin{array}{c}\text { PMCP/PMCH } \\
\text { area ratio }\end{array}$ \\
\hline $11 / 20 / 2003$ & 10 & Upwind & A-61 & $0.285 \pm 0.019$ & $1.888 \pm 0.22$ \\
& 15 & Downwind & N-79 & $0.274 \pm 0.038$ & $2.447 \pm 0.62$ \\
$11 / 25 / 2003$ & 21 & Upwind & SJV-120 & $0.864 \pm 0.057$ & $2.767 \pm 0.336$ \\
& 27 & Downwind & H-179 & $1.214 \pm 0.135$ & $3.329 \pm 0.486$ \\
$12 / 07 / 2003$ & 34 & Downwind & 29 & $1.212 \pm 0.210$ & $3.059 \pm 1.220$ \\
& 6 & Upwind & I-53 & $0.273 \pm 0.030$ & $1.919 \pm 0.21$ \\
& 25 & Downwind & K-151 & $0.298 \pm 0.032$ & $2.756 \pm 0.81$ \\
$12 / 14 / 2003$ & 30 & Downwind & 102 & $0.276 \pm 0.066$ & $1.980 \pm 0.13$ \\
& 11 & Upwind & H-102 & $0.243 \pm 0.014$ & $1.830 \pm 0.24$ \\
& 27 & Downwind & S-131 & $0.314 \pm 0.028$ & $2.460 \pm 0.60$ \\
& 32 & Downwind & DU98102 & $0.348 \pm 0.034$ & $2.506 \pm 0.51$ \\
\hline
\end{tabular}




\section{Results and Discussion}

Alkene and $\mathrm{NO}_{\mathrm{y}}$ Emission Rate Calculation

\section{A. Comparison of PMCP and PDCB Tracer Results}

An examination of the results in Table 4 shows that are three instances when the PMCP downwind concentration is elevated but the PDCB is not. If we plot the data, eliminating these three points (events, 15, 25, and 30 in Table 4), we get the plot shown in Figure 3. A regression analysis of the data yields a slope of $1.41 \pm 0.08$. But the PDCB value used here is only first isomer of PDCB which is only $72.5 \%$ of the released PDCB (the other isomer is being omitted due to chromatographic interference). If this is taken into account, the slope is $1.02 \pm 0.06$ which is comparable to an expected 1.037 based on the PFT flux rate and the measured PFT concentrations in the release cylinders.

The elevated PFT background in event 21 is due to changing winds. Until about 12 noon, the winds had been changing from northerly to the preferred S-SE direction. Tracer had been released since mid-morning and most likely the higher PFT background is from tracer that had been released when the winds were northerly and transported back towards the plant when the winds turned south.

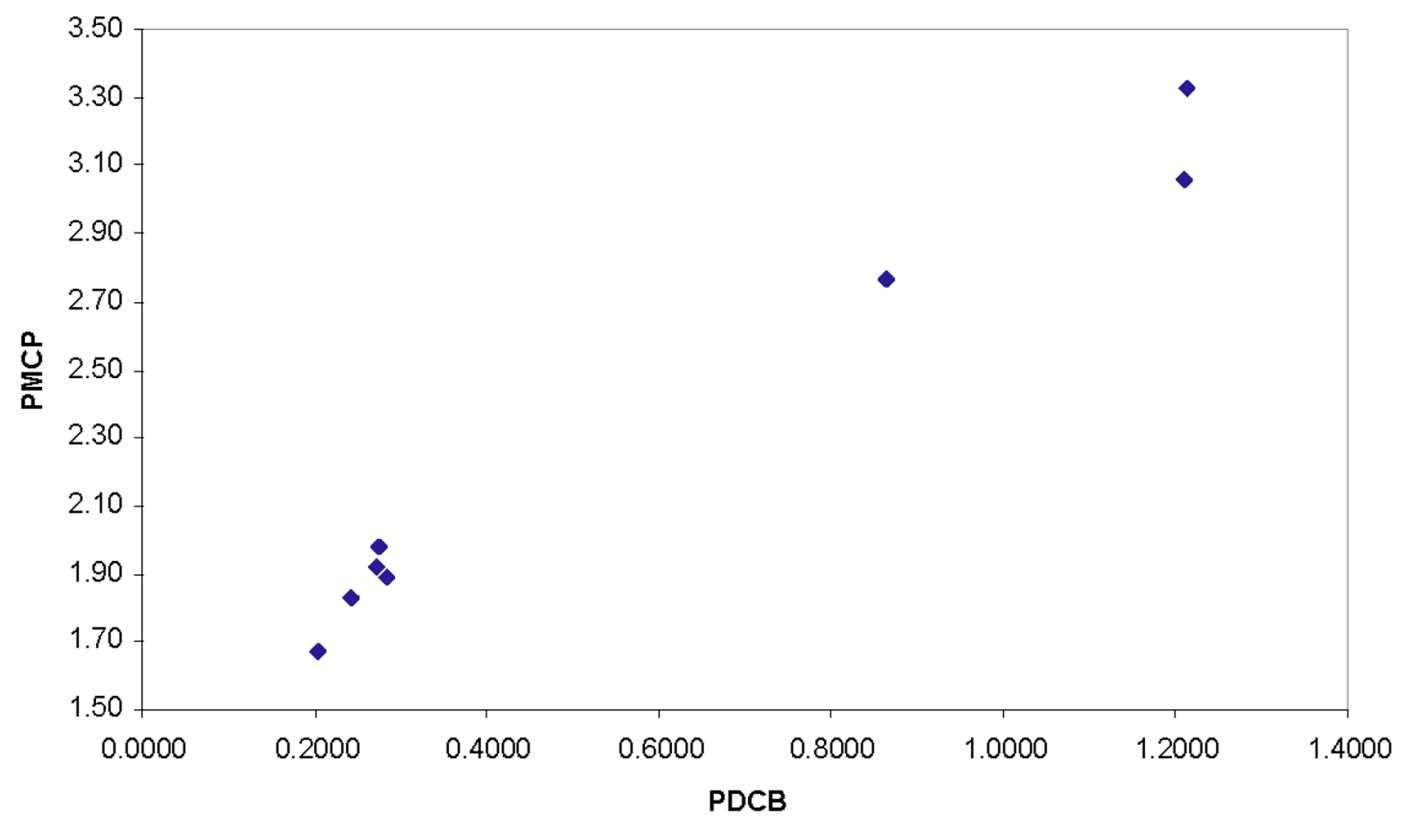

Figure 3. PMCP and PMCH correlation 
The three downind points that were eliminated from Figure 3 are interesting. The fact that PMCP was measurable and PDCB was not implies that there was a difference transport mechanisms for PDCB and PMCP. PDCB was released near the compressor in thermally hot core of the plant; PMCP was released at the water chiller inlet into a cooler plume. One interpretation is that there were two transport plumes, one straight up from the plant and at a higher elevation and the water chiller plume at a lower altitude. The water chiller plume is visible close to the plant and the sampling aircraft was visually biased to following this plume. Consequently, the remaining analysis will only use PMCP which was always in the plume that the aircraft was sampling. Most of the plume sampling was done at $1000 \mathrm{ft}$ MSL.

\section{B. Calculation of alkene emission flux from the Sweeny plant}

The calculation of the alkene fluxes requires the PMCP concentration, which is obtained from the PMCP/PMCH ratio, using a value of $5.0 \mathrm{ppq}$ for the concentration of $\mathrm{PMCH}$.

The first calculation is for ethene; the ethene concentrations are from the replicate canisters sent for hydrocarbon analysis. The results are given in Table 5. In some instances the ethene concentration is missing or is negative when the upwind background concentration is subtracted. Nonetheless, four ethene fluxes can be calculated and the average is $106 \pm 29 \mathrm{~kg} / \mathrm{hr}$. This can be compared to Sweeny estimate of $18 \mathrm{~kg} / \mathrm{hr}$ in (1); this estimate is based on summing emission factors in the Sweeny plant. The ethene $106 \pm 29 \mathrm{~kg} / \mathrm{hr}$ emission flux calculated here is only dependent on the accurately calibrated PFT emission flux and measured PFT concentration and is about 6 times higher than the Sweeny estimate.

\section{Table 5}

\begin{tabular}{|c|c|c|c|c|c|c|c|c|}
\hline \multirow[t]{2}{*}{ Date } & \multirow{2}{*}{$\begin{array}{l}\text { Event } \\
\text { Number }\end{array}$} & \multirow{2}{*}{$\begin{array}{l}\text { Sample } \\
\text { Type }\end{array}$} & \multicolumn{2}{|c|}{ Ethene } & \multicolumn{2}{|c|}{ PMCP conc } & \multicolumn{2}{|c|}{ Ethene flux } \\
\hline & & & $\mu g / m^{3}$ & bkg corr & $\mathrm{ppq}$ & bkg corr & $\mathrm{kg} / \mathrm{min}$ & $\mathrm{kg} / \mathrm{hr}$ \\
\hline \multirow[t]{2}{*}{$11 / 20 / 2003$} & 10 & Upwind & 0.3 & & 9.44 & 0.00 & 2.80 & 0.00 \\
\hline & 15 & Downwind & & & 12.24 & & & \\
\hline \multirow[t]{3}{*}{$11 / 25 / 2003$} & 21 & Upwind & 0.8 & 0.0 & 13.84 & & & \\
\hline & 27 & Downwind & 5.8 & 5.0 & 16.65 & 2.81 & 1.90 & 114 \\
\hline & 34 & Downwind & 2.5 & 1.7 & 15.30 & 1.46 & 1.25 & 75 \\
\hline \multirow[t]{3}{*}{$12 / 07 / 2003$} & 6 & Upwind & 0.8 & 0.0 & 9.60 & 0.00 & & \\
\hline & 25 & Downwind & 6.8 & 6.0 & 13.78 & 4.19 & 1.53 & 92 \\
\hline & 30 & Downwind & 5.7 & 4.9 & 9.90 & 0.31 & & \\
\hline \multirow[t]{4}{*}{$12 / 14 / 2003$} & 11 & Upwind & 2.5 & 0.0 & 9.15 & 0.00 & & \\
\hline & 27 & Downwind & 0.8 & -1.7 & 12.30 & 3.15 & & \\
\hline & 32 & Downwind & 10.0 & 7.5 & 12.53 & 3.38 & 2.37 & 142 \\
\hline & & \multicolumn{7}{|c|}{$\begin{array}{l}\text { PMCP flux } 1070 \times 10^{-6} \mathrm{~L} / \mathrm{min} \\
\text { Ethene flux } 106 \pm 29 \mathrm{~kg} / \mathrm{hr}\end{array}$} \\
\hline
\end{tabular}

The propene fluxes are similarly calculated and are given in Table 6. Again note the appearance of negative concentrations for propene when the background concentration is subtracted. For propene the calculated emission flux appears to vary by a factor of 4 to 6 over the different sampling dates, but are consistent in the two downwind samples taken on each 
sampling date. The propene flux on $11 / 25 / 2003$ averaged $82 \pm 1 \mathrm{~kg} / \mathrm{hr}$ and on 12/7/2003, averaged $277 \pm 55 \mathrm{~kg} / \mathrm{hr}$; clearly these are statistically different. Correspondingly, the ethene fluxes are more or less the same for these two dates, implying that the PFT analyses are not at fault. Two interpretations are

- The propene hydrocarbon analyses are at fault, perhaps on 12/7/04 there was an unresolved compound interfering with the quantification of propene.

- There was an actual change in propene emission flux at the plant. The sampling protocol required the operators at the Sweeny plant to immediately inform the flight crew of any unexpected outages; allowing the flight crew to cancel the sampling run. No outages were reported by the Sweeny plant operators.

The propene fluxes of $82 \pm 1 \mathrm{~kg} / \mathrm{hr}$ on $11 / 25 / 2003$ and $277 \pm 55 \mathrm{~kg} / \mathrm{hr}$ on 12/3/2003 can be compared to Sweeny summed emission factors estimate of $17 \mathrm{~kg} / \mathrm{hr}(1)$.

\section{Table 6}

\begin{tabular}{|c|c|c|c|c|c|c|c|c|}
\hline \multirow[t]{2}{*}{ Date } & \multirow{2}{*}{$\begin{array}{c}\text { Event } \\
\text { Number }\end{array}$} & \multirow{2}{*}{$\begin{array}{c}\text { Sample } \\
\text { Type }\end{array}$} & \multicolumn{2}{|c|}{ Propene } & \multicolumn{2}{|c|}{ PMCP conc } & \multicolumn{2}{|c|}{ Propene flux } \\
\hline & & & $\mu \mathrm{g} / \mathrm{m}^{3}$ & bkg corr & ppq & bkg corr & $\mathrm{kg} / \mathrm{min}$ & $\mathrm{kg} / \mathrm{hr}$ \\
\hline \multirow[t]{2}{*}{$11 / 20 / 2003$} & 10 & Upwind & 0.4 & 0.0 & 9.44 & 0.00 & & \\
\hline & 15 & Downwind & 0.8 & 0.4 & 12.24 & 2.80 & & \\
\hline \multirow[t]{3}{*}{$11 / 25 / 2003$} & 21 & Upwind & 0.8 & 0.0 & 13.84 & 0.00 & & \\
\hline & 27 & Downwind & 4.4 & 3.6 & 16.65 & 2.81 & 1.37 & 82 \\
\hline & 34 & Downwind & 2.7 & 1.9 & 15.30 & 1.46 & 1.39 & 84 \\
\hline \multirow[t]{3}{*}{$12 / 07 / 2003$} & 6 & Upwind & 0.6 & 0.0 & 9.60 & 0.00 & & \\
\hline & 25 & Downwind & 16.1 & 15.5 & 13.78 & 4.19 & 3.96 & 238 \\
\hline & 30 & Downwind & 2.1 & 1.5 & 9.90 & 0.31 & 5.26 & 316 \\
\hline \multirow[t]{4}{*}{$12 / 14 / 2003$} & 11 & Upwind & 1.6 & 0.0 & 9.15 & 0.00 & & \\
\hline & 27 & Downwind & 0.6 & -1.0 & 12.30 & 3.15 & & \\
\hline & 32 & Downwind & 4.3 & 2.7 & 12.53 & 3.38 & 0.85 & 51 \\
\hline & \multicolumn{4}{|c|}{ PMCP flux $1070 \times 10^{-6} \mathrm{~L} / \mathrm{min}$} & & & & \\
\hline
\end{tabular}




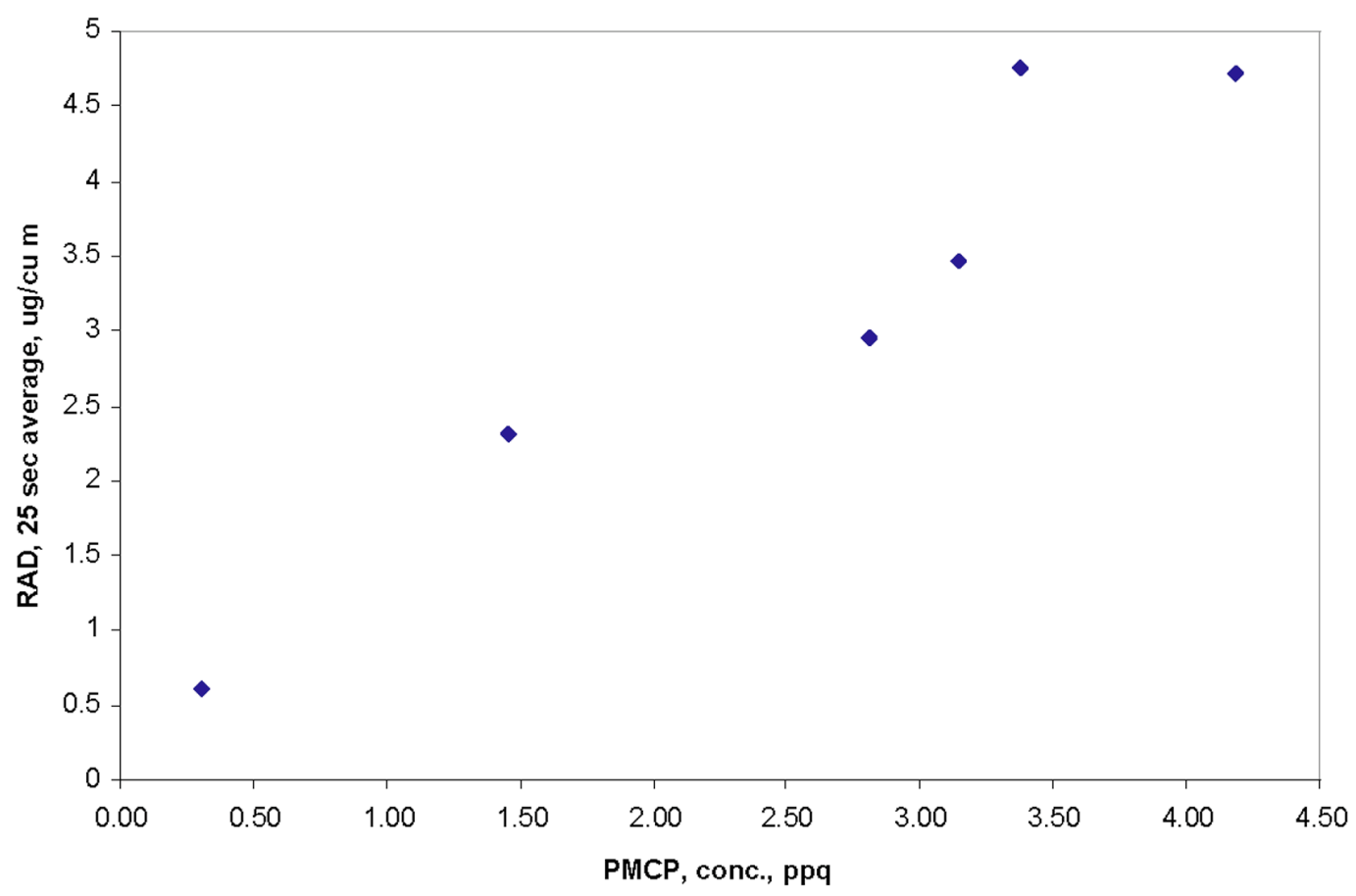

Figure 4

Further insight is seen in the additional plot given as Figure 4. This is plot of the PMCP concentration in the downwind samples for all of the runs versus the corresponding RAD measurement. Since the RAD is a real time monitor it was necessary to average the data; the RAD measurement in the plot is a 25 second average of 5 second data since the canister sampling time was 25 seconds. There is a very good correlation $\left(\mathrm{r}^{2}\right.$ is 0.92$)$ and the intercept is $0.42 \pm 0.44$ (it should be zero). The RAD measurement is a weighted sum of the ethene and propene concentrations. Guenther et al. (3) measured the relative ethene response as $15 \%$ of the propene response. If there had been a factor of 3 change in the propene emission between 11/25 and 12/7 sampling dates, then this would have been apparent in this plot of all of the data, but this plot has a very good correlation implying that the propene concentrations are possibly in error.

\section{Calculation of the $\mathrm{NO}_{y}$ emission flux from the Sweeny plant}

Aboard the sampling aircraft was a real-time $\mathrm{NO}, \mathrm{NO}_{2}$ and $\mathrm{NO}_{\mathrm{y}}$ monitor. The $\mathrm{NO}_{\mathrm{y}}$ emission flux was calculated from a 25 second average of 5 second $\mathrm{NO}_{\mathrm{y}}$ concentration data; the results are given in Table 7. Disregarding the flux determined on 12/7/03, the average flux is calculated as $230 \pm 40 \mathrm{~kg} / \mathrm{hr}$ and can be compared to 2000 TRNCC estimate of $554 \mathrm{~kg} / \mathrm{hr}$ (1). The estimate based on the PFT flux measurement is expected to be less accurate than the ethene and propene flux estimates, since the $\mathrm{NO}_{\mathrm{y}}$ concentration is not replicate canister based but rather an 25 second average of real-time data. Nonetheless, it has the right magnitude compared to the 2000 inventory estimate. 
Table 7

\begin{tabular}{|c|c|c|c|c|c|c|c|c|c|}
\hline \multirow[t]{2}{*}{ Date } & \multirow{2}{*}{$\begin{array}{c}\text { Event } \\
\text { Number }\end{array}$} & \multirow{2}{*}{$\begin{array}{l}\text { Sample } \\
\text { Type }\end{array}$} & \multicolumn{3}{|c|}{$\mathrm{NO}_{\mathrm{y}}$ conc. } & \multicolumn{2}{|c|}{ PMCP conc } & \multicolumn{2}{|c|}{ NO $_{y}$ flux } \\
\hline & & & ppb & $\mu \mathrm{g} / \mathrm{m}^{3}$ & bkg corr & ppq & bkg corr & $\mathrm{kg} / \mathrm{min}$ & tonnes/yr \\
\hline \multirow[t]{2}{*}{$11 / 20 / 2003$} & 10 & Upwind & 4.91 & & & 9.44 & 0.00 & & \\
\hline & 15 & Downwind & 4.91 & & & 12.24 & 2.80 & & \\
\hline \multirow[t]{3}{*}{$11 / 25 / 2003$} & 21 & Upwind & 3.43 & 6.46 & 0.00 & 13.84 & 0.00 & & \\
\hline & 27 & Downwind & 9.51 & 17.90 & 11.45 & 16.65 & 2.81 & 4.36 & 2292 \\
\hline & 34 & Downwind & 6.13 & 11.54 & 5.09 & 15.30 & 1.46 & 3.73 & 1961 \\
\hline \multirow[t]{3}{*}{$12 / 07 / 2003$} & 6 & Upwind & 3.90 & 7.35 & 0.00 & 9.60 & 0.00 & & \\
\hline & 25 & Downwind & 4.73 & 8.92 & 1.57 & 13.78 & 4.19 & 0.40 & 211 \\
\hline & 30 & Downwind & 3.57 & 6.72 & -0.63 & 9.90 & 0.31 & & \\
\hline \multirow[t]{4}{*}{$12 / 14 / 2003$} & 11 & Upwind & 7.16 & 13.48 & 0.00 & 9.15 & 0.00 & & \\
\hline & 27 & Downwind & 11.82 & 22.26 & 8.77 & 12.30 & 3.15 & 2.98 & 1567 \\
\hline & 32 & Downwind & 14.80 & 27.87 & 14.38 & 12.53 & 3.38 & 4.55 & 2395 \\
\hline & & \multicolumn{6}{|c|}{$\begin{array}{l}\text { PMCP flux } 1070 \times 10^{-6} \mathrm{~L} / \mathrm{min} \\
\mathrm{NO}_{\mathrm{y}} \text { flux } 2050 \pm 370 \text { tonnes } / \mathrm{yr}\end{array}$} & & \\
\hline
\end{tabular}

A possible explanation for the unrealistic results on $12 / 7 / 03$ is that the $\mathrm{NO}_{\mathrm{y}}$ plume was not coincident with PFT/ethene/propene plume; the $\mathrm{NO}_{\mathrm{y}}$ source at the power plant is 1900 feet away from the PFT/ethene/propane sources.

\section{$\underline{\text { Conclusions }}$}

1. The use of PFTs for the determination of fugitive emission fluxes has been successfully demonstrated in this field study. The two PFTs used in this study were well correlated in the canister samples when the two PFTS were in the same emission plume.

2. During certain meteorological conditions, two plumes were emanating from the Sweeny plant, one from the relatively hot core of the plant and other from the relatively cooler water chiller. The aircraft samples were more often from the cooler water chiller plume.

3. The ethene emission flux has been measured as $106 \pm 29 \mathrm{~kg} / \mathrm{hr}$, based on the ethene and PFT concentrations in the downwind aircraft canister samples and known PFT emission flux released inside the Sweeny plant. This is the average of three sampling dates, 11/25, $12 / 7$, and 12/14/2003. This is 6 times higher than the 2000 TRNCC estimate. 
4. The propene emission flux has similarly been measured as $82 \pm 1 \mathrm{~kg} / \mathrm{hr}$ on $11 / 25,277 \pm$ $55 \mathrm{~kg} / \mathrm{hr}$ on $12 / 7$ and $51 \mathrm{~kg} / \mathrm{hr}$ on $12 / 14 / 2003$. The varying results from different sampling dates is either a genuine variation in the plant propene emission rate or due to a large variability in the propene concentration in the hydrocarbon analyses. The high correlation between the PMCP and the RAD measurement of reactive alkenes, implies there are variabilities in the hydrocarbon analyses. The propene flux measurements are respectively $4.8,16.2$ or 3 times larger than the 2000 TRNCC estimate.

5. The $\mathrm{NO}_{\mathrm{y}}$ emission flux has been estimated as $230 \pm 40 \mathrm{~kg} / \mathrm{hr}$ based on the PMCP concentration in the aircraft sampled canister and a 25 second average of the $\mathrm{NO}_{\mathrm{y}}$ realtime concentration. It can be compared to the 2000 TRNCC estimate of $554 \mathrm{~kg} / \mathrm{hr}$.

\section{References}

1. Effect of petrochemical industrial emissions of reactive alkenes and $\mathrm{NO}_{\mathrm{x}}$ on tropospheric ozone formation in Houston, Texas, Ryerson, T. B., et al., J. Geophys. Res. 108 (D8), 4249, doi:10.1029/2002JD003070 (2003).

2. Perfluorocarbon tracer technology. Dietz, R. N., In Regional and Long-Range Transport of Air Pollution, Lectures of a course held at the Joint Research Centre, Ispra, Italy, September 15-19, 1986, S. Sandroni (Ed.), pp. 215-247.

3. Eddy covariance measurements of isoprene fluxes, Guenther, A. and Hills, A. J., J. Geophys. Res. 103 (D11), 13,145-13,152 (1998). 